\title{
Commercializing the Unpredictable: Perspectives From Wildlife Watching Tourism Entrepreneurs in Sweden
}

\section{Lusine Margaryan \& Sandra Wall-Reinius}

To cite this article: Lusine Margaryan \& Sandra Wall-Reinius (2017) Commercializing the Unpredictable: Perspectives From Wildlife Watching Tourism Entrepreneurs in Sweden, Human Dimensions of Wildlife, 22:5, 406-421, DOI: 10.1080/10871209.2017.1334842

To link to this article: https://doi.org/10.1080/10871209.2017.1334842

\section{曲 Published online: 12 Jun 2017.}

Submit your article to this journal $๘$

III Article views: 342

Q View related articles

View Crossmark data \lceil

Citing articles: 6 View citing articles 지 


\title{
Commercializing the Unpredictable: Perspectives From Wildlife Watching Tourism Entrepreneurs in Sweden
}

\author{
Lusine Margaryan and Sandra Wall-Reinius \\ Department of Tourism Studies and Geography, Mid Sweden University, Östersund, Sweden
}

\begin{abstract}
Tourism companies that offer wildlife watching experiences share a unique property-they build their business on a promise they have no guarantee of fulfilling (showing wild animals). The factor of luck becomes important, as evident in the advertisement texts of wildlife watching tours. Understanding commercialization of uncontrollable natural phenomena (wild animals) in a similarly uncertain natural setting (wilderness) is the aim of our article. In this illustrative case study, we examine wildlife watching companies in Sweden, focusing on free ranging bear, moose, wolf, roe-deer, beaver, and seal. Through interviews and participant observations with eight wildlife watching entrepreneurs, we elaborate on the following major themes that help understand specific challenges associated with these businesses: lack of control as an inherent property of wildlife watching tourism, agency and continuous negotiation of uncertainties within the operational setting, importance of guide performances and "secondary" experiences, and using uncertainty as a way of enhancing authenticity.
\end{abstract}

\section{KEYWORDS}

Nature-based tourism; nature commodification; uncertainty; wildlife watching

\section{Introduction}

In the last three decades, populations of wildlife have recovered in many parts of Europe, and in Sweden, this has resulted in more large terrestrial mammals than has ever been recorded (Thulin, Malmsten, \& Ericsson, 2015). Returning large herbivores and predators have ignited local interest toward wildlife watching and using wildlife for tourism development (Helmer, Saavedra, Sylvén, \& Schepers, 2015; Johansson et al., 2016). Although a growing number of tourism companies see this as a lucrative opportunity and now integrate animal-related experiences into their tours, little is known about how these businesses manage uncertainties associated with commercializing encounters with freeranging wildlife, especially in Northern Europe.

Wildlife photographer Konsta Punkka (2016) said: "My work is a balance between luck and patience. Because you can never predict nature." In the context of nature's unpredictability, luck and patience indeed seem to be indispensable factors. Of these two factors, tourism companies that offer wildlife watching experiences can hardly afford patience, being obliged to deliver animal sightings on a given date at a given time. The factor of luck seems to become highly important. It is commonplace to examine the promotional materials of wildlife watching tours and notice the verbiage is replete with "luck," "hopefully," "chance," "occasionally," "no guarantee," and similar words, signifying uncertainty 
and unpredictability. As it is often explicitly stated on their websites, these companies cannot be held liable for such factors as weather, the impact of other businesses, forestry, livestock in the area, hunting quotas, and other external circumstances (e.g., Exclusive Adventure, 2017). It is usually stressed that a company can never fully guarantee an encounter with the desired animal. Although performances within tourist spaces cannot be totally controlled in general, this is particularly pronounced in nature-based tourism (Knight, 2009; Lück, 2003, 2015; Manfredo, 2008; Orams, 1996). Nature-based tourism companies build their businesses around commercialization of largely uncontrollable phenomena in a complex and uncertain operational setting, contested by multiple actors (Fredman, Wall-Reinius, \& Grundén, 2012; Knight, 2009; Manfredo, 2008; Vespestad \& Lindberg, 2011). This uniqueness makes nature-based tourism different from many businesses in general and other types of tourism in particular.

The importance of navigating, adapting to, and mitigating uncontrollable factors as an essential part of the commercial processes in the context of nature-based tourism has not received sufficient attention in the recent tourism literature. Academic research within the tourism service and marketing literature has primarily focused on the tourism setting parameters within the immediate control of managers (as is evident in the meta-analyses by Mari \& Poggesi, 2013; Wakefield \& Blodgett, 2016). In nature-based tourism research, a considerable body of literature has been accumulated on the experiences of tourists in nature, but comparatively less is known about strategies of nature-based tourism companies to account for uncertainties associated with designing these experiences, especially in the Euroepan context. Furthermore, research regarding nature-based tourism has been skewed toward the demand, rather than the supply perspective (Fredman \& Tyrväinen, 2010; Lundmark \& Müller, 2010). The aim of our article, therefore, is to examine companies in Sweden to contribute to understanding how wildlife watching tourism (hereafter WWT) service providers manage uncertainties associated with commercializing uncontrollable natural phenomena.

WWT is a type of nature-based tourism that attempts to use nature in a nonconsumptive way (in contrast to hunting or fishing) and whose growing popularity and economic importance have been widely acknowledged (Curtin \& Kragh, 2014; Markwell, 2015; Newsome, Moore, \& Dowling, 2013). WWT has been defined as "[a] human recreational engagement with wildlife wherein the focal organism is not purposefully removed or permanently affected by the engagement" (Duffus \& Dearden, 1990, p. 215). We chose WWT from a wide range of nature-based types of tourism due to its high dependence on largely uncontrollable factorsnot only the setting (e.g., weather, landscape, infrastructure, other users), but also the primary experience itself (i.e., human-wildlife encounter) is beyond the immediate control of the service providers. The main research questions guiding our study were:

(1) How do WWT companies manage uncertainties related to behavior of free-ranging wildlife?

(2) How do WWT companies manage uncertainties within their operational setting?

\section{Managing uncertainty while commercializing nature}

It has been argued that commercialization of nature is usually preceded by economic framing, monetization, and appropriation (Gómez-Baggethun \& Ruiz-Pérez, 2011). This is 
a process that is rather clearly visible in traditional extractive industries, but is far from straightforward in tourism. This particularly refers to the appropriation stage, which usually presupposes privatization and well-defined property rights over a certain resource. In the case of nature-based tourism, the main resource often has intrinsic public good or common pool characteristics, making appropriation almost impossible. ${ }^{1}$ This is especially relevant in the case of Sweden where citizens have a right to access any nature areas for recreation purposes (discussed in more detail below). In this case, tourism has to operate under conditions of "incomplete" or "contested" commodification, a context where external and internal barriers exist to physical alienation and privatization of an entity on the market (Castree, 2003). To improve understanding of this challenging context, we employ the concept of uncertainty.

Attention toward uncertainty and risk in the service and marketing literature started to develop in the 1960s and resulted in two streams of research where one stream used these concepts interchangeably and the other insisted on separating them (Quintal, Lee, \& Soutar, 2010). In the economic and social science literature, uncertainty is often viewed as an independent concept. Hofstede (2001) argued that risk requires a concrete event and the probability of it happening may be estimated. Uncertainty, on the other hand, does not allow calculating probabilities since the event itself might be unknown. Becker and Knudsen (2005) differentiated among risk (where both the event and the related probability are known), uncertainty (where the event is known, but the probabilities are not), and pervasive uncertainty (where neither the events nor probabilities are known). Uncertainty has also been examined on three levels: state, effect, and response uncertainty (Becker, \& Knudsen, 2005; Milliken, 1987). State uncertainty relates to uncertainty of the environment, whereas effect and response uncertainty highlight the respective lack of knowledge within a firm about possible effects and response options. Based on the economic and organizational literature, it has been suggested that when dealing with general uncertainty on all of these levels, actively managing available information is important, whereas organizational routines become crucial when dealing with pervasive uncertainty (Becker \& Knudsen, 2005). These insights are used in our study to improve understanding of the WWT context.

In the context of WWT, companies have to deal with uncertainties on all of the described levels, including uncertainties within their operational setting (involving a complex interplay of natural and human actors), their main product (human-animal encounter), and the related effects on their business and the available response options. Importance of availability of different kinds of information under uncertain conditions in the WWT context has been demonstrated (Knight, 2009; Lück, 2003, 2015; Manfredo, 2008; Orams, 1996). We, therefore, assume that a promising way to understand complexities associated with the commercialization of uncontrollable natural phenomena through tourism is to understand how WWT companies deal with uncertainty from the perspective of managing information, such as communication with other actors and examining their routines on the ground during wildlife watching tours.

\section{Specifics of WWT}

Humans have always been dependent on, fascinated by, and inspired by animals (as evidenced by the earliest prehistoric art such as in the caves of Lascaux and Altamira). 
Watching wild animals, especially charismatic megafauna, has become an increasingly popular tourism attraction in many areas around the world, which is related to growing urbanization, increasing environmental awareness and, ironically, shrinking populations of wildlife species worldwide (Curtin \& Kragh, 2014; Johansson et al., 2016). Consequently, attention toward commercialization of wild animals through tourism (in consumptive and nonconsumptive ways) has also been increasing in the tourism literature (e.g., Curtin \& Kragh, 2014; Duffy, 2015; Fennell, 2011; Manfredo \& Larson, 1993; Markwell, 2015). Resources of WWT can be categorized as abundance of large animals, iconic species, and areas with high biodiversity (Higginbottom \& Buckley, 2001). In this article, we focus on companies dependent on the second type of resources (i.e., iconic species) in light of the recent recovery of megafauna and a growing tourist interest toward viewing free-ranging wildlife in Sweden.

From an economic perspective, WWT holds the promise of a typical win-win marketbased solution (which gained popularity especially since the advance of the sustainability agenda in the 1990s), suggesting that promoting this type of business can generate income for local communities and simultaneously support conservation efforts (Buckley, 2010; Cousins, Evans, \& Sadler, 2009; Curtin \& Kragh, 2014). This model of sustainable tourism, however, has to function within the complexities and uncertainties of the real world, where conflicts of interest may arise in cases of negligible economic benefits, economic leakages, and competition with other land use interests (e.g., agriculture, energy production, logging) and livelihoods (e.g., competing businesses) or lifestyles (e.g., hunting). Furthermore, conditions of high uncertainty, arising not only from the operational setting, but also the specifics of the very object of commercialization, makes WWT a rather unique and challenging form of business. In this context, business interests often override the conservation and community priorities, and WWT ends up exploiting the very resource on which it depends (Fennell, 2011; Markwell, 2015). This is relevant not only to developing countries that have attracted more research attention in this regard (e.g., Cousins et al., 2009; Markwell, 2015), but also developed countries.

\section{The context of Sweden}

Located on the Scandinavian Peninsula, Sweden is known for its abundant natural resources and relatively scarce human population, sometimes labeled as "Europe's last wilderness" and "Europe's Alaska" (Sylvén, 2015). Although Sweden has a long history of outdoor recreation, it has been primarily dominated by the traditional activities of hunting, fishing, mushroom and berry picking, as well as active outdoor sports, such as cross-country skiing or hiking, not necessarily in a commercial context. Along with this, there is evidence suggesting that interest in commercial nature-based tourism and its nonextractive forms, such as WWT, is also gaining popularity. For example, in a recent quantitative analysis of around 600 nature-based tourism companies in Sweden, 23\% stated that bird and wildlife watching is important or very important for their annual sales (Fredman \& Margaryan, 2014). With the recent increase in the populations of megafauna in Scandinavia, WWT has the potential to become a lucrative business opportunity (Helmer et al., 2015).

Sweden is a country where the four big predators of Europe can be found: brown bear (Ursus arctos), gray wolf (Canis lupus), lynx (Lynx lynx), and wolverine (Gulo gulo). In 
addition, Sweden has a large population of moose (Alces alces), which has an iconic status in Swedish culture, is the main game species, and is an omnipresent symbol in tourism merchandise. From the WWT perspective, a decade ago Sweden was primarily associated with bird-watching, whereas knowledge of using megafauna for tourism was lacking (Ednardsson, 2006; Naturvårdsverket, 2008). This situation has clearly been changing, with a growing number of companies adding WWT tours.

Sweden has another unique feature-the Right of Public Access (formulated in the 1970s and included in the Swedish Constitution in 1994). Typical to only a handful of other countries (mostly Nordic), this right specifies that everyone has unlimited access to nature areas for the purposes of recreation, including such activities as hiking, boating, tent camping, and berry and mushroom picking (Naturvårdsverket, 2014). This makes the case of Sweden particularly interesting given that commercialization of wildlife occurs in a relatively open access context, defying opportunities for appropriation and control. The successful navigation of a multifunctional landscape becomes crucial given that the multiple heterogeneous resource use interests (e.g., hunting, fishing, forestry, farming) have a potential of being either complementary or conflicting with WWT businesses.

Sweden is still a rather immature WWT destination and it is possible that the market is dominated by "casual" rather than "serious" wildlife watching tourists (Cole \& Scott, 1999; Martin, 1997). Many WWT companies are based near large urban areas and offer short daily trips, thus catering to a large share of tourists for whom wildlife watching was, most likely, not the primary travel motivation. These tourists have different expectations and preferences affecting the nature of the WWT product. In this study, we focused only on perspectives of WWT entrepreneurs.

\section{Methods}

In this article, we wanted to gain a better understanding of how WWT businesses deal with complexities associated with the commercialization of uncontrollable natural phenomena by looking at examples in Sweden. Based on the suggestion by Becker and Knudsen (2005), we assumed that to achieve this, one approach is to understand how WWT companies deal with uncertainty (i.e., to find out the key components of their operational setting, how they manage communication and information flows, and what kind of routines they employ during trips). We employed two main empirical techniques, interviews (in-depth, semi-structured) and participant observations, focusing on ownermanagers and guides of WWT companies in Sweden. The interview method was used for generating narratives of participants on the study topic, whereas participant observation enabled documenting routines, performances, and naturally occurring talks in the field. Supplementary background data were collected from websites of WWT companies included in the sample and beyond. Combining these qualitative methods enabled us to strengthen our insights through triangulation (i.e., the practice of using various methods to elucidate as much of the study phenomena as possible).

Data were collected in July and August 2016. This is the peak tourist season in Sweden and the time of year when popular wildlife species are active. According to existing estimates, there are at least 60 companies in Sweden for whom bird and wildlife watching is a very important tourist product, but this does not imply that all of these companies 
specialize in WWT (Fredman \& Margaryan, 2014). Based on our online search, previous knowledge, and consultations with two regional tourism bureaus, we identified 22 active companies in Sweden that feature wildlife prominently on their websites and specialize in WWT products. These companies were contacted by email. Out of this sample, we eventually recruited a sample of eight companies who work with a range of the most typical Swedish wildlife and are located in various parts of the country from north to south (Table 1).

The interviews were conducted with the owner-managers (or partial owners) of WWT businesses, who also often work as guides themselves. The interview questions were developed based on the aim of the research and covering the following topics: general information (details about the company, content and design of the wildlife tours, their main focus), object of commercialization (importance of various animals, if/how animal behavior is influenced, what happens when the animal does not appear), and operational setting (importance of various man-made components, management of information flows and communication with other resource users and actors in the area, perceived power to act on the uncertainties within the setting). All interviews were recorded and transcribed verbatim. All of the interviews were conducted and recorded respecting the principles of informed consent, anonymity, and confidentiality.

Participant observations included 1-day and 2-day wildlife watching trips with the selected companies. During the participant observations, one of the researchers had an opportunity to observe the work of the guides, closely interact with them, conduct informal interviews, and experience a typical WWT tour package in its entirety. Routines of the guides and naturally occurring conversations between the guide and

Table 1. Description of WWT companies and data collection methods.

\begin{tabular}{|c|c|c|c|c|}
\hline Participants* & Primary wildlife focus & Secondary wildlife focus & $\begin{array}{l}\text { Location in } \\
\text { Sweden }\end{array}$ & $\begin{array}{l}\text { Interaction } \\
\text { method }\end{array}$ \\
\hline $\begin{array}{l}\text { Company } 1, \\
\text { Mikael }\end{array}$ & Moose (Alces alces) & $\begin{array}{l}\text { Roe deer (Capreolus capreolus), wild boar } \\
\text { (Sus scrofa) }\end{array}$ & South-west & Interview \\
\hline $\begin{array}{l}\text { Company } 2, \\
\text { Anna }\end{array}$ & Beaver (Castor fiber) & - & South & Interview \\
\hline $\begin{array}{l}\text { Company } 3, \\
\text { Martin }\end{array}$ & $\begin{array}{l}\text { Gray seal (Halichoerus } \\
\text { grypus), white-tailed } \\
\text { eagle (Haliaeetus } \\
\text { albicilla) }\end{array}$ & Various aquatic birds & South & Interview \\
\hline $\begin{array}{l}\text { Company 4, } \\
\text { Peter }\end{array}$ & $\begin{array}{l}\text { Brown bear (Ursus } \\
\text { arctos) }\end{array}$ & $\begin{array}{l}\text { Golden eagle (Aquil } \\
\text { a chrysaetos) }\end{array}$ & North & Interview \\
\hline $\begin{array}{l}\text { Company 5, } \\
\text { Kristin }\end{array}$ & $\begin{array}{l}\text { Brown bear (Ursus } \\
\text { arctos) }\end{array}$ & $\begin{array}{l}\text { Fox (Vulpes vulpes), } \\
\text { various birds }\end{array}$ & North & $\begin{array}{l}\text { Interview } \\
\text { Participant } \\
\text { observation }\end{array}$ \\
\hline $\begin{array}{l}\text { Company 6, } \\
\text { Maria }\end{array}$ & Moose (Alces alces) & $\begin{array}{l}\text { Roe deer (Capreolus capreolus), wild boar } \\
\text { (Sus scrofa) }\end{array}$ & South-west & $\begin{array}{l}\text { Informal interview } \\
\text { Participant } \\
\text { observation }\end{array}$ \\
\hline & $\begin{array}{l}\text { Moose (Alces alces), } \\
\text { brown bear (Ursus }\end{array}$ & $\begin{array}{l}\text { Roe deer (Capreolus capreolus), red deer } \\
\text { (Cervus elaphus), }\end{array}$ & North & $\begin{array}{l}\text { Informal } \\
\text { interview }\end{array}$ \\
\hline Sara & arctos) & beaver (Castor fiber) & & $\begin{array}{l}\text { Participant } \\
\text { observation }\end{array}$ \\
\hline $\begin{array}{l}\text { Company 8, } \\
\text { Daniel }\end{array}$ & $\begin{array}{l}\text { Gray wolf (Canis lupus), } \\
\text { moose (Alces alces), red } \\
\text { deer (Cervus elaphus), } \\
\text { lynx (Lynx lynx), various } \\
\text { birds }\end{array}$ & $\begin{array}{l}\text { Beaver (Castor fiber), fox (Vulpes vulpes), roe } \\
\text { deer (Capreolus capreolus) }\end{array}$ & South-west & $\begin{array}{l}\text { Informal } \\
\text { interview } \\
\text { Participant } \\
\text { observation }\end{array}$ \\
\hline
\end{tabular}

Note. *All names are pseudonyms. 
tourists during uncertain situations was the main focus of the observations, providing rich data for this study. The tours were attended either by the researcher alone or a maximum of two other tourists at a time, which enabled establishing rapport and close interaction with the guides over a prolonged period of time (up to 20 hours). Field notes were taken during and after each trip. The observation foci were: (a) role of the guides in co-creating the WWT experience, and (b) strategies of the guides in navigating uncontrollable situations. The guides were aware of the researcher's identity and the overarching idea of the research, but no specific details about the research questions were discussed, so we believe that the routine behavior and narratives of the guides were not significantly compromised. Furthermore, given that the participating researcher was a foreigner in Sweden, that researcher may have been ascribed a regular tourist identity by the guides and treated accordingly.

We continued accumulating empirical data while simultaneously interpreting and (re) constructing them until we reached what is referred to as informational isomorph or theoretical saturation (i.e., further collection of empirical materials did not yield additional insights; Lincoln \& Guba, 1985; Silverman, 2013). The interviews were treated as narratives through which the interviewees described their reality, whereas participant observations gave first-hand insights into realities the participants wanted to actively construct through performances, routines, and conversations (Silverman, 2013). Both interview transcripts and participant observation field notes were organized, systematized, and coded with the help of Dedoose qualitative data analysis software. Segmentation and reassembling the data with the aim to transform them into findings was done based on the three-step coding process recommended by Boeije (2009). The principles of analytic induction, constant comparison, and comprehensive data treatment were adopted while collecting and thematically analyzing the empirical materials (Silverman, 2013).

\section{Results}

\section{Uncertainty as an inherent property of WWT}

Lack of control was one of the central themes that emerged from the data. This relates, first and foremost, to the main experience offered (i.e., the animal encounter). The inherent uncertainty of the environment and animals was continuously emphasized by the companies. Martin (Company 3) said: "If the animals don't show up then we say that nature is unpredictable." The guides would routinely start the tour with an explicit statement that there is no guarantee to encounter any wildlife. Prior to embarking on the tour, the tourists are expected to accept the possibility of not seeing any animals during the trip.

Creating a promise while risking not living up to tourist expectations (even if they are supposed to be mitigated with disclaimers) was one of the most visible tensions in this context of WWT. For example, Sara (Company 7) offered a bear watching tour. Her WWT product presupposes spotting bears from a car while crisscrossing a labyrinth of forest roads. Upon our initial contact, she was quick to warn that the chance of a bear sighting was rather low, suggesting that spotting other animals, such as a moose or a roe deer, might be more likely. Our trip, however, was not rich in any animal sightings, except for a glimpse of a moose behind the trees. Sara tried various alternative routes and options with little success. 
She was visibly stressed and seemed genuinely relieved when we stated that there was no disappointment with the trip. Daniel (Company 8) also confessed that handling uncertainty is not easy: "It can be quite stressful. People come with their expensive cameras, they have paid for the flight, have paid me, and expect that they should see the animal."

One strategy to mitigate uncertainty is to influence animal behavior via attracting them with bait. Baiting is currently practiced in Sweden primarily with bears and certain raptors, after obtaining special permission from the Regional Administrative Board. To attract bears, bait (fruit or leftovers from slaughterhouses and fishing industries) is placed in the same spot on a nearly daily basis. Special wildlife watching hides are installed in the area to enable comfortable spotting. Even with baiting, however, animal sightings cannot be guaranteed, not only due to the animal behavior per se, but also the entire sociopolitical context around this issue (discussed below).

Kristin (Company 5), whose business is based on bear watching with baiting, is a landowner and, therefore, enjoys a significant advantage compared to the majority of the WWT companies, who operate on others' land. Her company has the power to implement actions of direct control (e.g., through blocking the forest road leading to the hide to prevent unsanctioned vehicle access) and to manage the forestry and hunting activities in a way benign to the bears and the WWT space. However, even though the sociopolitical context is less problematic for Kristin, she still has to grapple with the uncertainties regarding animal sightings:

\footnotetext{
The most important thing for us is the percentage of bear sights. It is that simple. If we have a female bear with cubs coming tonight, I will post it on Facebook, and tomorrow there will be Norwegian tourists here. ... We try different things. I think that we just have to keep on trying, based on previous experience and research. We are trying to do our best, but there is a big uncertainty for sure. And we are nervous about it. (Kristin, Company 5)
}

The majority of Swedish WWT companies, however, do not involve baiting. The chance of an animal sighting, therefore, depends heavily on the knowledge and skills of guides who study the wildlife and collect all kinds of related information. In this regard, a successful operation of WWT involves practical measures of turning nature into a desired tourist space. The tourist spaces, in turn, cannot be isolated and are open heterogeneous landscapes influenced by forestry, energy production, mining, and agriculture, as well as by other actors such as local authorities, residents, landowners, hunters, reindeer herders, and other tourists and businesses. Negotiation of such complex spaces demands resilience and adaptability, creative solutions, and establishment and continuous maintenance of relationships with other users.

\section{Negotiating the uncertainties of WWT operational setting}

It is well known that the tourism sector is characterized by small and medium (and often micro) enterprises who consider their ability to act on external constraints to be rather limited (Lundberg \& Fredman, 2012). This sentiment was also recurrent among the companies we interviewed: "We are too small. In the outdoor business we are very small if you compare us to the others. We don't have the power of influence in the big arena" (Anna, Company 2). Daniel (Company 8) was not happy with how the forests were managed in his operational setting. He pointed at the landscape and said: "Next year all 
this beauty will be gone, and these beautiful forest roads will be destroyed. ... We don't have any say in the activities of the forestry companies."

As a rule, the companies are dependent on infrastructure they have little power to influence. This encompasses everything from the global tourist transportation systems to the basic local infrastructure, such as forest roads, overnight cabins, or trails. Mikael (Company 1), for example, operates in a protected area and felt grateful for the infrastructure found there and its maintenance by the local authorities. He said:

They keep the paths accessible in the nature reserves, provide the firewood, and the things birdwatching towers, which definitely add to the guest experience. And if you go a bit north, you have all the cabins, it's absolutely amazing.... It really helps, because instead of camping for five nights, you can have two nights in a tent and two nights in a cabin, without any extra costs.

Although the WWT companies benefit from infrastructure built and maintained by the local authorities, landowners, or forest companies, they have limited capacity to influence it if it does not align with their interests. Infrastructure might affect the accessibility of tourist spaces in rather unpredictable ways. Anna (Company 2), for example, mentioned that tourists now have significant problems reaching her location given that the new regional minibuses do not allow luggage on board. What is also interesting, on another end of this spectrum, is that too much accessibility might also become undesirable. Infrastructure might compromise the "wilderness experience" that WWT companies strive to create. Mikael (Company 1) explained: "I don't think they should add more [infrastructure]. Because the accessibility is already really good. Maybe they could even do a bit less ... it does make it feel less wild."

Lack of control, however, does not imply a lack of initiative and agency on behalf of the WWT companies, aiming to act on the uncertainties within their operational setting. On the contrary, successful functioning within these uncertainties requires continuous efforts. Peter (Company 4) operates a bear watching business on someone else's land (which is the case with the majority of nature-based tourism entrepreneurs in Sweden) and described his complex relationship with other actors (i.e., the landowner and forest companies):

Well, we need forest for the bear watching, for our arrangement. It is actually always a problem with the landowner regarding cutting trees.... We always have discussions with the landowners and forest companies. If you don't find natural environment, the bears won't be here. And we are always fighting, calling, writing emails, letters-anything, just to keep the forest owner up to date. ... At the moment we have a discussion with one company. They want to clear-cut the whole forest behind our hide. If they do it, it would be a disaster. It would be absolutely.... Probably I would have to close down all these 10 years of work with the bears.

Peter also has to negotiate his operational setting with hunters and the county administration:

Hunting is something that we always have to watch out for, we have to be updated all the time. There is bear hunting in this area. And we always try to have a discussion with them [hunters], ask them not to hunt so close. Last year they shot five bears in our area. All we can do is to have a discussion with them. This is very important for tourism. We want the county administration to understand this. We have to create some regulations concerning hunting. There is a lot to do. 
It is apparent that the WWT companies have to navigate a complex operational setting where the built environment is intertwined with the social and political context of the area (e.g., protection regime, ownership status, power). Keeping the setting favorable and managing its uncertainties, therefore, requires continuous management of information flows, monitoring and maintenance of relationships with other resource users, and creativity, knowledge, and skills while dealing with the tourists.

\section{Guide performances and secondary experiences}

The importance of tour guides for nature experiences has been widely acknowledged in the tourism literature (Arnould, Price, \& Tierney, 1998; Lück, 2003, 2015; Mossberg, 2008; Orams, 1996; Vespestad \& Lindberg, 2011; Weiler \& Black, 2015). In our study, the guides play a crucial role in managing uncertainty during the WWT tours. They rely on experience, knowledge, and skills in tracking, spotting, identifying, attracting the animals, and interpreting their behavior for tourists. The guides also make use of modern technologies, such as global positioning system (GPS) tracking or short message service (SMS) alerts, to maximize the chances for sightings.

If animals do not appear, the guides have the responsibility to manage the disappointment of tourists and co-create value via various strategies. What becomes evident in this context is the importance of "secondary," but more guaranteed experiences (by the analogy of primary and secondary tourist products, discussed in Ben-Dalia, CollinsKreiner, \& Churchman, 2013). Although the opportunity to see certain wildlife species is the main experience advertised (and arguably the main reason the tourists book the trip), the companies attempt to de-emphasize it through offering other supplementary experiences. As a rule, the companies offer, for example, a traditional Swedish dinner accompanied by storytelling, in-depth information about the species in focus, history of the region, and sharing personal experiences. Martin (Company 3) said: "We have some other things to show, even if we don't see these animals. We still have the sailing experience, which should be an experience in itself." Similarly, Anna (Company 2) said: "We organize a beaver evening, so we think that the tourists get something from us, because we talk about beavers a lot. It is not just about seeing them."

Furthermore, the guides try to find evidence of animal presence, such as tracks, hairs, droppings, prey remnants, or dens to create an experience of animal encounters indirectly. They might use props, such as stuffed animals, skulls, or hides to enhance the feeling of proximity to the animal and provide a tactile experience. Showing videos or photographs accompanied by storytelling might be used to create a vicarious WWT experience. During our trip with Daniel (Company 8), we looked for wolf tracks, after which he offered setting up a camera trap and promised to share the photos and videos for free in case an animal gets "caught." During the night, Daniel imitated wolf howling to trigger a wolf response. He said:

I want the guests to go back and say not that "I could see the wolf", but rather "I could feel the wolf." ... I don't want people to come only to see some animal. One couple, for example, wanted to come here only to photograph lynx, and I told them directly that you won't be able to see it. And they didn't come.

Other animals, which do not have "star quality" (i.e., charismatic megafauna) or are simply more common, such as roe deer, fox, hare, various birds, or insects, also play an 
important role in creating value for tourists in the absence of the main focal species. Martin (Company 3), explained that in addition to the main species in focus (gray seals and white-tailed eagles), they try to draw tourists' attention to every species they meet on the way and tell something interesting about each of them, thus making them contribute to the tourist experience. In fact, none of the interviewed companies wanted to describe their product as simply "wildlife watching." They insisted that they offer "a whole package" or "more than just wildlife watching." Mikael (Company 1), for example, said:

We try to deliver a quality product and have customer satisfaction. And, we do this by trying to take all of the worries away from the tourists, to offer an all-inclusive package. Of course, the activity [WWT] itself is a big part. But, we also try to do it in the nicest environment, to encourage the group to interact. We help them get to know each other and have a great day outdoors, do activities, meet people in a lovely environment-all in one package.

Here it seems that the guide performances play a crucial role in externalizing the main desired experience (i.e., watching the animal) as a mystified and unpredictable surprise, while the secondary experience de facto becomes the main one. The initial centrality of the promise to see the animal is, nevertheless, indispensable to making the entire package possible. Žižek (2003) described this mechanism of desire and product marketing within modern capitalism through the widely popular commodity-a Kinder surprise chocolate egg: consumers do not simply buy chocolate plus a bonus (a toy inside). From the beginning, consumers aim at the hidden surprise and, as a result, are also able to fully enjoy the chocolate, which is not tainted by desires and expectations. The surprise becomes the "it" factor; the promise of something more than just a product. By this logic, aiming at a higher goal (i.e., the animal sighting with a high degree of uncertainty), the tourists then co-create value with the help of guides through simple and rather mundane outdoor activities. The guides here seem to undertake a crucial role of keeping this mechanism working. If the desired animal does not show up, the guides attempt to co-create value with the tourists through their established repertoire of routines, such as offering a traditional dinner, stimulating social interaction, storytelling, showing evidence of animal presence, and using props and media to enhance the wilderness feeling.

\section{Unpredictability as authenticity}

Authenticity has been a well-researched and contested concept in the tourism literature, including in a nature-based context (Carrier, 2004; Knudsen, Rickly, \& Vidon, 2016). In the WWT context, an authentic experience would typically include observing nondomesticated animals in their natural environment and exhibiting natural behavior. Demand for such experiences has been documented to grow with changing environmental values, shifting away from artificial, zoo- and circus-like attractions (Markwell, 2015). In this regard, it can be argued that a destination with (semi)captive animals, while guaranteeing close encounters, compromises the "authenticity" of the wildlife experience that many WWT companies try to offer. Consequently, the unpredictability of animal sightings becomes a signifier of an "authentic wilderness," a proof that animal autonomy is not violated. Not showing up is presented as the evidence that the animals are genuinely wild (i.e., they maintain the ability to exercise their own will). The companies want to emphasize this factor, saying: "We tell our guests that these [seals] are wild animals and 
we can't make them appear on command" (Martin, Company 3) or "It is up to them [bears], if they want to do something else, they will do it" (Peter, Company 4). Peter further elaborated, "They [tourists] are not disappointed if they go back home without seeing any bears. Because they know it is wildlife. And this is how it should be. Otherwise you can just go to a zoo."

It is interesting to note that baiting was not viewed in this context as compromising the authenticity of animal behavior. The respondents emphasized that animals still have the option to exercise their "free will" by coming and going as they please (and the tourist season itself lasts only two or three summer months). Furthermore, the guides educate the tourists about an entire set of behavior rules, which serve a double purpose. On the one hand, they aim to prevent animals from becoming habituated, whereas, on the other hand, they simultaneously enhance the tourists' feeling of being in the out-of-ordinary environment and authentic wilderness. This includes, for example, encouraging tourists to whisper, make as little noise as possible, and avoid leaving the hide or walking in front of the hide (Ratamäki \& Peltola, 2015). It can be argued, therefore, that unpredictability of animal behavior and the elements within the context of WWT, becomes, in fact, synonymous with authenticity, which is used by the guides to enhance the wilderness experience.

\section{Discussion}

In our article, we examined complexities associated with the commercialization of natural phenomena by looking at how WWT companies in Sweden manage the related uncertainties. Overall, it can be argued that although not much different from other types of tourism in terms of structure (i.e., requires transportation, accommodation, catering, guides), WWT has a uniquely high dependence on operational setting features with public good characteristics - a context with a high degree of uncertainty that demands creativity and agency on behalf of the entrepreneurs. In addition to the uncertainties of the natural environment, the WWT companies have to navigate and balance their operational setting with other resource users and their interests and values, while also respecting conservation interests.

One strategy to mitigate the contextual uncertainties is to maximize and actively manage information (Becker \& Knudsen, 2005). Our findings showed that the WWT companies creatively and pro-actively manage information flows around their businesses on different levels. First, the companies try to attract tourists with impressive pictures of focal animals on their websites while simultaneously emphasizing the uncertainty in their product description through relevant rhetoric. Second, when dealing with tourists face-toface, the companies attempt to prepare them for the uncertainties of wildlife watching and mitigate their expectations before embarking on the trip. Third, the companies constantly collect and process information regarding the intentions and actions of multiple other resource users (e.g., local authorities, transportation companies, forestry industry, hunters) and maintain a dialogue with them to mitigate the effect and response uncertainties. Fourth, the WWT companies we interviewed were actively collecting and disseminating information regarding the state of wildlife in their region, attempting to negotiate a successful common resource use and maximize the frequency of animal sightings. Although populations of charismatic megafauna in Sweden are not as dense as in some 
wilderness hot-spots, the lack of wildlife did not come up as a major problem for businesses. In contrast, the sociopolitical context was perceived as a more challenging factor. Constant monitoring of the operational setting and its negotiation with other resource users requires continuous effort and is not uncommonly accompanied by the feelings of frustration and powerlessness on behalf of the entrepreneurs.

Another uncertainty mitigation strategy that we examined was the on-site routines of the guides. One distinct strategy was to offer "secondary," but more guaranteed experiences, skillfully shifting the attention of tourists away from the animal encounter, which becomes de-emphasized. In fact, none of the companies offered wildlife experiences without, for example, including a traditional dinner in a special location, a forest walk, a boat ride, an extensive nature interpretation session, or other activities emphasizing social interaction and storytelling about the local history, culture, and nature. In fact, there was hardly ever a purely wildlife watching tour; it almost always included strong cultural components or was even de facto dominated by these components. This illustrates the inherent dilemma of experience co-creation discussed by Ellis and Rossman (2008), who pointed out that on one hand, the tourists should be allowed to create their own experiences, but on the other hand, poorly staged events and unmanaged environments do not yield rewarding experiences on their own. The guides, therefore, play a crucial role in creatively orchestrating this process of managing tourist expectations and co-creating experiences. This is achieved through engaging in more predictable social routines that are, however, not free from tension and stress for the guides.

Nature commercialization processes are closely related or, one can even argue, inversely correlated with authenticity, since "commodification is said to destroy the authenticity" (Cohen, 1988, p. 372). In the context of "contested" or "incomplete" commodification, unpredictability becomes synonymous with a high degree of authenticity, representing a manifestation of nature's forces and constructing a tourist space as "wilderness." Despite a profound dismantling of wilderness as an idealized pristine space outside of civilization and human impact, it remains a sought-after experience and a strong tourism marketing focus (Cousins et al., 2009; Wall-Reinius, 2009, 2012). Unpredictability of animal behavior signals minimal interference with natural processes and animal welfare. Thus, skillfully oscillating on this predictable-secondary and unpredictable-primary experiential continuum, WWT entrepreneurs creatively turn this challenge into an opportunity to add more value to their product and legitimize their operations as sustainable.

Overall, it can be expected that in the areas where wildlife, and particularly charismatic megafauna, are (still) free-ranging, tourism will be considered a business opportunity. In the context of Europe where the wildlife's comeback has been a relatively recent phenomenon, tourism companies currently operate under conditions of high uncertainty, lacking the heritage of more controlled wildlife tourism settings. With the growing popularity of wildlife watching, however, tourism businesses might be motivated to minimize uncertainty under pressure to deliver closer and more guaranteed encounters. In many parts of the world, the tourism industry is known to employ exploitative practices in its drive to increase chances of animal sightings and provide tourists with opportunities to closely observe, touch, feed, or ride animals, disregarding the well-being of wildlife species (Fennell, 2011; Markwell, 2015). Future attention, therefore, should be paid to the evolving ways of nature commercialization through tourism and whether, for example, the factor of authenticity in the wildlife watching experiences can contribute to minimizing negative 
impacts of tourism on wildlife. Further research focusing on tourists, their attitudes toward uncertainty, and their agency in co-creating WWT experiences when the target animal is absent, will add further insights into the complexities associated with nature commercialization through tourism.

\section{Note}

1. More artificial environments, such as enclosed safari parks or zoos that sometimes fall into the definition of nature-based tourism, are not included in this analysis.

\section{References}

Arnould, E. J., Price, L. L., \& Tierney, P. (1998). Communicative staging of the wilderness servicescape. The Service Industries Journal, 18, 90-115. doi:10.1080/02642069800000034

Becker, M. C., \& Knudsen, T. (2005). The role of routines in reducing pervasive uncertainty. Journal of Business Research, 58, 746-757. doi:10.1016/j.jbusres.2003.10.003

Ben-Dalia, S., Collins-Kreiner, N., \& Churchman, A. (2013). Evaluation of an urban tourism destination. Tourism Geographies, 15, 233-249. doi:10.1080/14616688.2011.647329

Boeije, H. (2009). Analysis in qualitative research. Thousand Oaks, CA: Sage.

Buckley, R. (2010). Conservation tourism. Wallingford, UK: CABI.

Carrier, J. (2004). Ecotourism and authenticity. Current Anthropology, 45, 483-498. doi:10.1086/ 422082

Castree, N. (2003). Commodifying what nature? Progress in Human Geography, 27, 273-277. doi:10.1191/0309132503ph428oa

Cohen, E. (1988). Authenticity and commoditization in tourism. Annals of Tourism Research, 15, 371-386. doi:10.1016/0160-7383(88)90028-X

Cole, J. S., \& Scott, D. (1999). Segmenting participation in wildlife watching: A comparison of casual wildlife watchers and serious birders. Human Dimensions of Wildlife, 4(4), 44-61. doi:10.1080/ 10871209909359164

Cousins, J. A., Evans, J., \& Sadler, J. (2009). Selling conservation? Scientific legitimacy and the commodification of conservation tourism. Ecology and Society, 14, 32-52. doi:10.5751/ES-02804140132

Curtin, S., \& Kragh, G. (2014). Wildlife tourism: Reconnecting people with nature. Human Dimensions of Wildlife, 19, 545-554. doi:10.1080/10871209.2014.921957

Duffus, D., \& Dearden, P. (1990). Non-consumptive wildlife-oriented recreation: A conceptual framework. Biological Conservation, 53, 213-232. doi:10.1016/0006-3207(90)90087-6

Duffy, R. (2015). Nature-based tourism and neoliberalism: Concealing contradictions. Tourism Geographies, 17, 529-543. doi:10.1080/14616688.2015.1053972

Ednardsson, M. (2006). Attitudes toward large carnivores and carnivore tourism among tourism entrepreneurs in Sweden. Revue De Géographie Alpine, 94(4), 58-67. doi:10.3406/rga.2006.5591

Ellis, G. D., \& Rossman, J. R. (2008). Creating value for participants through experience staging: Parks, recreation, and tourism in the experience industry. Journal of Park \& Recreation Administration, 26(4), 1-20.

Exclusive Adventure (2017). Booking information. Retrieved from http://exclusiveadventure.se/en/ bokning/

Fennell, D. A. (2011). Tourism and animal ethics. New York, NY: Routledge.

Fredman, P., \& Margaryan, L. (2014). The supply of nature-based tourism in Sweden: A national inventory of service providers. Östersund, Sweden: ETOUR.

Fredman, P., \& Tyrväinen, L. (2010). Frontiers in nature-based tourism. Scandinavian Journal of Hospitality and Tourism, 10, 177-189. doi:10.1080/15022250.2010.502365

Fredman, P., Wall-Reinius, S., \& Grundén, A. (2012). The nature of nature in nature-based tourism. Scandinavian Journal of Hospitality and Tourism, 12, 289-309. doi:10.1080/15022250.2012.752893 
Gómez-Baggethun, E., \& Ruiz-Pérez, M. (2011). Economic valuation and the commodification of ecosystem services. Progress in Physical Geography, 35, 613-628. doi:10.1177/0309133311421708

Helmer, W., Saavedra, D., Sylvén, M., \& Schepers, F. (2015). Rewilding Europe: A new strategy for an old continent. In H. Pereira \& L. Navarro (Eds.), Rewilding European landscapes (pp. 171-191). New York, NY: Springer.

Higginbottom, K., \& Buckley, R. (2001). Viewing of free-ranging land-dwelling wildlife. Gold Coast, Queensland, Australia: CRC for Sustainable Tourism.

Hofstede, G. (2001). Culture's consequences: Comparing values, behaviors, institutions and organizations across nations. Thousand Oaks, CA: Sage.

Johansson, M., Dressel, S., Kvastegård, E., Ericsson, G., Fischer, A., Kaltenborn, B., ... Sandström, C. (2016). Describing human-wildlife interaction from a European perspective. Human Dimensions of Wildlife, 21, 158-168. doi:10.1080/10871209.2016.1110648

Knight, J. (2009). Making wildlife viewable: Habituation and attraction. Society \& Animals, 17, 167184. doi:10.1163/156853009X418091

Knudsen, D. C., Rickly, J. M., \& Vidon, E. S. (2016). The fantasy of authenticity: Touring with Lacan. Annals of Tourism Research, 58, 33-45. doi:10.1016/j.annals.2016.02.003

Lincoln, Y. S., \& Guba, E. G. (1985). Naturalistic inquiry. Newbury Park, CA: Sage.

Lück, M. (2003). Education on marine mammal tours as agent for conservation-But do tourists want to be educated? Ocean \& Coastal Management, 46, 943-956. doi:10.1016/S0964-5691(03) 00071-1

Lück, M. (2015). Education on marine mammal tours-But what do tourists want to learn? Ocean \& Coastal Management, 103, 25-33. doi:10.1016/j.ocecoaman.2014.11.002

Lundberg, C., \& Fredman, P. (2012). Success factors and constraints among nature-based tourism entrepreneurs. Current Issues in Tourism, 15, 649-671. doi:10.1080/13683500.2011.630458

Lundmark, L., \& Müller, D. K. (2010). The supply of nature-based tourism activities in Sweden. Tourism, 58, 379-393.

Manfredo, M. J. (2008). Who cares about wildlife? Social science concepts for exploring humanwildife relationships and conservation issues. New York, NY: Springer.

Manfredo, M. J., \& Larson, R. A. (1993). Managing for wildlife viewing recreation experiences: An application in Colorado. Wildlife Society Bulletin, 21, 226-236.

Mari, M., \& Poggesi, S. (2013). Servicescape cues and customer behavior: A systematic literature review and research agenda. The Service Industries Journal, 33, 171-199. doi:10.1080/ 02642069.2011 .613934

Markwell, K. (2015). Animals and tourism: Understanding diverse relationships. Bristol, UK: Channel View.

Martin, S. R. (1997). Specialization and differences in setting preferences among wildlife viewers. Human Dimensions of Wildlife, 2(1), 1-18. doi:10.1080/10871209709359083

Milliken, F. J. (1987). Three types of perceived uncertainty about the environment: State, effect, and response uncertainty. The Academy of Management Review, 12, 133-143.

Mossberg, L. (2008). Extraordinary experiences through storytelling. Scandinavian Journal of Hospitality and Tourism, 8, 195-210. doi:10.1080/15022250802532443

Naturvårdsverket (2008). Rovdjursturism. Tre rapporter med kartläggning, litteraturstudie och juridisk analys. Rapport 5687. Bromma: CM Gruppen.

Naturvårdsverket (2014). The right of public access-This is allowed. Retrieved from http://Www. Naturvardsverket.Se/En/EnjoyingNature/The-Right-Of-Public-Access/This-Is-Allowed

Newsome, D., Moore, S., \& Dowling, R. (2013). Natural area tourism: Ecology, impacts and management. Bristol, UK: Channel View.

Orams, M. B. (1996). A conceptual model of tourist-wildlife interaction: The case for education as a management strategy. The Australian Geographer, 27, 39-51. doi:10.1080/00049189608703156

Punkka, K. (2016). Wildlife photography: Capturing portraits of your favorite animals. Skillshare. Retrieved from https://www.skillshare.com/kpunkka

Quintal, V., Lee, A., \& Soutar, N. (2010). Risk, uncertainty and the theory of planned behavior: A tourism example. Tourism Management, 31, 797-805. doi:10.1016/j.tourman.2009.08.006 
Ratamäki, O., \& Peltola, T. (2015). Drama over large carnivores. In K. Markwell (Ed.), Animals and tourism: Understanding diverse relationships (pp. 180-194). Bristol, UK: Channel View.

Silverman, D. (2013). Doing qualitative research: A practical handbook. London, UK: Sage.

Sylvén, M. (2015). Rewilding Lapland. Creating a sustainable future for Europe's largest unspoiled natural and cultural treasure. Rewilding Europe project brochure. Retrieved from https://www. rewildingeurope.com/wp-content/uploads/2015/12/Rewilding-Lapland-EN.pdf

Thulin, C. G., Malmsten, J., \& Ericsson, G. (2015). Opportunities and challenges with growing wildlife populations and zoonotic diseases in Sweden. European Journal of Wildlife Research, 61, 649-656. doi:10.1007/s10344-015-0945-1

Vespestad, M. K., \& Lindberg, F. (2011). Understanding nature-based tourist experiences: An ontological analysis. Current Issues in Tourism, 14, 563-580. doi:10.1080/13683500.2010.513730

Wakefield, K. L., \& Blodgett, J. (2016). Retrospective: The importance of servicescapes in leisure service settings. Journal of Services Marketing, 30, 686-691. doi:10.1108/JSM-08-2016-0291

Wall-Reinius, S. (2009). Protected attractions: Tourism and wilderness in the Swedish mountain region. (Unpublished doctoral dissertation). Stockholms Universitet, Stockholm, Sweden.

Wall-Reinius, S. (2012). Wilderness and culture: Tourist views and experiences in the Laponian world heritage area. Society \& Natural Resources, 25, 621-632. doi:10.1080/08941920.2011.627911

Weiler, B., \& Black, R. (2015). Tour guiding research: Insights, issues and implications. Bristol, UK: Channel View.

Žižek, S. (2003). Human rights in a chocolate egg. Cabinet Magazine, 11. Retrieved from http:// www.cabinetmagazine.org/issues/11/kinderEgg.php 